\title{
TRÍADE DA SENSIBILIZAÇÃO AMBIENTAL: O USO DAS NOVAS TECNOLOGIAS ALIADA À PRÁTICA DE EDUCAÇÃO AMBIENTAL E O ENSINO NA GEOGRAFIA
}

Silvia Patricia Marques ${ }^{1}$ Carla Luciane Blum Vestena ${ }^{2}$

Resumo: Diante dos avanços tecnológicos que temos sido expostos na última década e o crescente consumismo, principalmente nas cidades, surge a necessidade da conscientização, quanto a consequente produção de resíduos sólidos. Porém ao observarmos à prática da Educação Ambiental desde sua implementação no currículo básico brasileiro, notamos que esta não têm atendido adequadamente a proposta original, limitando-se a projetos isolados. Este ensaio remete a reflexão de uma proposta, ou seja, a tríade da sensibilização. Nosso argumento se baseia no uso das novas tecnologias aliada à prática da Educação Ambiental e o Ensino na Geografia, como elementos integrados para a sensibilização ambiental.

Palavras-chave: Ensino de Geografia; Educação Ambiental; Novas Tecnologias.

${ }^{1}$ Universidade Estadual do Centro Oeste, E-mail: prof.silviapaty@gmail.com

2 Universidade Estadual do Centro Oeste, E-mail: clbvestena@gmail.com 


\section{Introdução}

A tecnologia está presente no trabalho, no lazer e em casa, as informações são transmitidas quase que em tempo real, temos acesso ao mundo na tela de nossos notebooks, tablets e smartphones, o que têm gerado um consenso no que diz respeito ao ensino de geografia, não há como fugir do uso desses recursos, precisamos urgentemente adequarmos nossa prática pedagógica à natureza das relações que têm sido estabelecidas no espaço e tempo que nos inserimos e às expectativas dessa geração tecnológica e conectada que está em nossas salas de aula e dessa forma trazermos ao aluno um conhecimento significativo.

Sobretudo, há uma dinâmica entre os sistemas de ações e os sistemas de objetos, levando a criação de novos objetos e novas ações, que atendam as novas necessidades criadas a partir dessa dinâmica, transformando assim o espaço (SANTOS, 1999).

Contudo, se o espaço geográfico está em constante transformação, e nós com nossas criações e trabalho somos os protagonistas desse processo, necessitamos de uma Educação Ambiental pautada no espaço e que possibilite ao aluno ver se como parte dessa dinâmica e principalmente como agente transformador deste, e que suas ações sobre o espaço têm consequências, conceder-lhe um olhar atento e crítico de forma que esteja imune aos agentes alienantes de nossa sociedade, que na maioria das vezes nos impulsionam a consumir cada vez mais independente de nossa necessidade e dos impactos que esse consumo exagerado possam causar.

Embora, Santos (1999), se mantivesse cético no que diz espeito ao uso das tecnologias no trabalho, ele via que apesar do uso das tecnologias no trabalho aumentasse a cada dia, o lugar do homem ainda era essencial, o papel de pensar é claro.

Dessa maneira, o papel do professor não se extingue, mas toma uma nova postura com o uso das novas tecnologias enquanto recursos didáticos, cabendo a este o papel de pensar as formas de se utilizar desses recursos e selecionar no meio de tanta informação o que é relevante e o que é dispensável.

A esse respeito, Moran menciona que educar é aprender a gerenciar um conjunto de informações, ou seja,

[...] é torná-las algo significativo para cada um de nós, isto é, o conhecimento. Hoje nós temos inúmeras informações e um conhecimento bem menor, porque estas nos escapam, estão soltas, não sabemos reorganizá-las. O conhecimento é isso. Além de gerenciar a informação, é importante aprender a gerenciar também sentimentos, afetos, todo o universo das emoções (MORAN, 2001, p.22). 
Sabemos que toda reforma envolve uma mudança de postura e preparação para que a mudança seja efetiva e benéfica, dessa forma vemos a necessidade da capacitação dos professores de forma que estes estejam aptos a aplicarem os recursos tecnológicos de forma adequada e eficiente, dando a eles uma utilidade de formar cidadãos conscientes de seu papel no mundo.

Portanto, pretende-se com esse ensaio refletir sobre a tríade da conscientização ambiental, apontando para a articulação das Novas Tecnologias aliada à pratica da Educação Ambiental e o ensino na Geografia. Para tanto a pesquisa abordará cada um dos componentes da tríade, de forma a evidenciar os elos que os ligam e a potencialidade dessa composição.

\section{A Geografia enquanto saber que atende as necessidades sociais}

O conhecimento e o domínio do espaço são vitais à vida humana, e a geografia nasce dessa necessidade humana, onde o homem precisa conhecer e dominar o espaço, logo esse conhecimento transforma-se em subjugação da natureza pelo homem, porém hoje, após séculos e séculos de exploração da natureza pelo ser humano, é vital ao homem conhecer os limites do meio ambiente e aprender a respeitar a natureza. Onde a geografia apresenta o potencial para ser um instrumento de informação e conscientização humana, conforme nos aponta Mendonça (2004):

A geografia é, sem sombra de dúvidas, a única ciência que, desde a sua formação, se propôs ao estudo da relação entre os homens e o meio natural do planeta - meio ambiente, atualmente, em voga é propalado na perspectiva que engloba 0 meio natural e o social" (MENDONÇA, 2004, p. 22-23).

Desde a antiguidade o conhecimento geográfico, têm proporcionado ao homem a sobrevivência, a proteção de seu território e a conquista de novos territórios. Atualmente a geografia tem nos proporcionado conhecermos melhor as relações entre 0 homem e a natureza, porém até nossos dias o conhecimento geográfico percorreu um longo processo histórico evolutivo.

O conhecimento geográfico é sistematizado no século XIX pelos alemães Carl Ritter (1979 - 1859) e Alexander Von Humboldt (1769 - 1859), tinham como centro de suas pesquisas a natureza, podemos dizer que eles trouxeram nova abordagem ao espaço que vinha sendo ocupado e transformado pelo homem, desde então o conhecimento geográfico tornou-se essencial ao desenvolvimento da sociedade, através da descrição do espaço e da confecção de cartas, conhecimento este muito útil ao poder político e militar.

As escolas geográficas, modernas alemã (determinista) e francesa (possibilista) são fundadas por Friedrich Ratzel (1844 - 1904) e Paul Vidal de La Blache $(1845$ - 1918) respectivamente, essa forma de fazer geografia chamada de positivista se esgotou com o passar do tempo, o advento Revbea, São Paulo, V. 11, № 4: 336-349, 2016. 
capitalista e as guerras mundiais dando assim espaço para novas correntes do pensamento geográfico como a pragmática ou quantitativa, a geografia crítica, vertente de raízes marxista e a geografia humanística. Ao observarmos cada corrente é possível observar o anseio por uma nova forma de se produzir o conhecimento geográfico, bem como as principais diferenças entre elas.

Na corrente pragmática, segundo Moraes (1983):

[...] o temário geográfico poderia ser explicado totalmente com o uso de métodos matemáticos. Todas as questões aí tratadas - as relações e interações de fenômenos de elementos, as variações locais da paisagem, a ação da natureza sobre os homens etc. - seriam passíveis de ser expressas em termos numéricos (pela mediação de suas manifestações) e compreendidas na forma de cálculos. Para eles, os avanços da estatística e da computação propiciam uma explicação geográfica (MORAES, 1983, p.103).

Quando se fala em geografia Crítica, não se pode deixar de falar que esta teve por base o pensamento Marxista e surge como resposta à crise que pairava sobre a geografia quantitativa. Nesta corrente o espaço é movido pelas contradições existentes e por um processo dialético, sua base teórica é o materialismo histórico-dialético. Nessa concepção "os autores da Geografia crítica vão fazer uma avaliação profunda das razões da crise; são os que acham fundamental evidenciá-la. Vão além de um questionamento puramente acadêmico do pensamento tradicional buscando suas raízes sociais" (MORAES, 1983, p.112-113).

$\mathrm{Na}$ concepção humanística, também conhecida por geografia da percepção, valoriza-se a construção subjetiva da noção de espaço valoriza primordialmente o indivíduo, que estabelece relações com os lugares. Esta corrente também ficou conhecida como "Topofilia" conforme conceito estabelecido por Yu-fu Tuan, "Topofilia é o elo afetivo entre a pessoa e o lugar ou ambiente físico. Difuso como conceito, vívido e concreto como experiência pessoal'2.

Podemos dizer ao observarmos a evolução do pensamento geográfico, que em quase todo o seu percurso enquanto ciência e até mesmo antes de sua sistematização, que este encontra-se intimamente ligado as questões do meio ambiente. $\mathrm{Na}$ geografia tradicional a descrição do espaço através da observação da natureza, na geografia crítica os processos de apropriação do espaço pelo homem, que vê a natureza como recurso e fonte de renda, na geografia humanística o espaço passa a ser entendido pelo olhar do indivíduo e consequentemente é resultado da relação (afetiva) que este tem com o meio,

\footnotetext{
2 Topofilia, um estudo de percepção, atitudes e valores do meio ambiente, 1980, p.5.
}

revista brasileira educação ambiental 
de forma que é impossível concebermos uma Educação Ambiental alheia ao espaço e, por conseguinte da geografia.

Diferentemente da geografia militar com seus propósitos de defender e conquistar territórios a geografia escolar nasce no século XIX sem grandes pretensões onde serve apenas aos interesses das classes dominantes promovendo a mistificação do espaço através discursos ideológicos, durante muito tempo a escola foi privilégio de uma minoria rica, porém mesmo com a popularização do acesso ao ensino, não houve grandes mudanças nesse quadro, pois a educação que se oferece ainda hoje é mais de memorização do que de produção de conhecimento. Lacoste (1976) em sua obra descreve a geografia escolar de sua época como:

Uma disciplina maçante, mas antes de tudo simplória, pois, como qualquer um sabe, "em geografia nada há para entender, mas é preciso ter memória..." De qualquer forma, após alguns anos, os alunos não querem mais ouvir falar dessas aulas que enumeram, para cada região ou para cada país, o relevo - clima - vegetação população - agricultura - cidades - indústrias (Lacoste, 1976, p.21).

Embora muitas coisas tenham sido mudadas no decorrer das décadas, no que diz respeito ao ensino de geografia, cremos que ainda necessitamos transpor alguns obstáculos, para despertar do interesse do aluno e sensibilizálo ambientalmente. A geografia enquanto ciência caminha lado a lado com as necessidades da sociedade em cada tempo, o conhecer o espaço permite ao homem condições de melhor desfrutá-lo, acontece que nesse início do século XXI chegamos ao um nível muito elevado de apropriação dos recursos naturais e de emissão de resíduos, cabendo a geografia agora trilhar o caminho da conscientização, principalmente no que diz respeito à geografia escolar, a fim de criar novas formas de olhar e desfrutar o espaço, mas de que maneira?

Santos (2001, p.25) afirma que, “(...) no lugar de uma geografia meramente descritiva, os novos tempos dão lugar a uma realidade vivida pelo educando e a sua situação nesse contexto", com base nessa afirmação cremos que devemos apostar numa geografia escolar que parte do cotidiano do aluno e das situações aventadas na mídia diariamente, levando o aluno a compreender que as catástrofes ambientais não estão alheias a sua realidade, mas que o planeta é um sistema interligado e que nossas ações são refletidas e sentidas globalmente. 


\section{Educação Ambiental: uma necessidade após vinte anos de implementação}

A Medida que as técnicas e a tecnologia evoluem, maior é o impacto da ação humana sob o meio ambiente. Mas o que é o meio ambiente? Qual sua importância na manutenção da vida humana? Como nasce a Educação Ambiental?

Conforme Lima (2007) a resolução CONAMA 306:2002 faz menção de pontos de extrema importância afim de se definir meio ambiente: "Meio Ambiente é o conjunto de condições, leis, influência e interações de ordem física, química, biológica, social, cultural e urbanística, que permite, abriga e rege a vida em todas as suas formas".

Já na ISO 14001:2004 o meio ambiente é definido como: "circunvizinhança em que uma organização opera, incluindo-se ar, água, solo, recursos naturais, flora, fauna, seres humanos e suas inter-relações.

De forma que através destas definições conclui-se que é o meio ambiente que possibilita a vida e sua manutenção, logo sua preservação é imperativa.

Para Lima (2007), cabe a sociedade a responsabilidade da preservação do meio ambiente, logo, é necessário que as atitudes desta sociedade sejam pensadas de forma que se produzam o menor impacto possível, a custo de mantermos as condições de vida no presente e principalmente no futuro.

No Artigo 225 da Constituição Federal Brasileira, expõe a seguinte abordagem:

Todos têm direito ao meio ambiente ecologicamente equilibrado, bem de uso comum do povo e essencial à qualidade de vida impondo-se ao Poder público e à coletividade o dever de defendê-lo e preservá-lo para as presentes e futuras gerações BRASIL (1988).

Sendo assim, entende-se que a sociedade não consegue se manter sem água potável, clima ameno e ar puro, não há possibilidade de sobrevivência sem a manutenção do meio ambiente, porém pessoas, organizações e países portam-se de forma depredatória, como se o desenvolvimento e a qualidade de vida dependessem apenas do capital que se amontoa através da exploração dos recursos naturais, não há preocupação com os dejetos produzidos pelas grandes empresas, nem mesmo com o consumismo que só aumenta devido à padrões estabelecidos pela mídia, produzindo assim grande quantia de resíduos sólidos, ficando cada vez mais evidente a necessidade da Educação Ambiental de forma contundente e permanente, nos diversos estabelecimentos de ensino, de nossa sociedade.

A Educação Ambiental surge da preocupação dos movimentos ecologistas e também dos ambientalistas com a prática de conscientização, que chame a atenção da sociedade para a finitude e a distribuição desigual dos 
recursos naturais, e que seja capaz de engajar os cidadãos em ações sociais ambientalmente necessárias, seja de preservação ou uso consciente dos recursos naturais, salienta Carvalho (2006).

De forma a atender a proposta advinda desses movimentos dos ecologistas e ambientalistas, e também dos indicativos dos eventos internacionais, a Conferência de Tbilisi (1977) e de Moscou (1987) e nacional a Eco-92, em1997, foram elaborados os Parâmetros Curriculares Nacionais $(\mathrm{PCNs})^{3}$, com o tema "Convívio Social, Ética e Meio Ambiente", sendo assim insere-se nos currículos do ensino fundamental a dimensão ambiental como um tema transversal.

Como consequência dos acontecimentos supracitados, promulga-se a Lei 9.795/1999, que prescreve os conceitos e princípios para a Educação Ambiental.

Art. 1 - Entendem-se por Educação Ambiental os processos por meio dos quais o indivíduo e a coletividade constroem valores sociais, conhecimentos, habilidades, atitudes e competências voltadas para a conservação do meio ambiente, bem de uso comum do povo, essencial à sadia qualidade de vida e sua sustentabilidade.

Art. 2 - A Educação Ambiental é um componente essencial e permanente da educação nacional, devendo estar presente, de forma articulada, em todos os níveis e modalidades do processo educativo, em caráter formal e não-formal.

A Educação Ambiental é alocada nos documentos legais do governo, chamados temas transversais, são cadernos temáticos que segundo Torales (2006) seguem os moldes da reformulação utilizada na Espanha em 1990, cujo objetivo era romper com a fragmentação do saber escolar, pois esses temas seriam o que excede cada uma das disciplinas escolares para além dos muros da escola, objetivando uma educação formadora de cidadãos.

Para Vestena (2003) apesar do avanço significativo na institucionalização da Educação Ambiental é possível observar que os projetos desenvolvidos nas instituições escolares não têm atendido aos fins propostos pela lei promulgada em 1999, ficando então uma lacuna entre a proposta e o que é realmente realizado.

Sato (2001) debate os desafios da Educação Ambiental, a partir de algumas lacunas na prática desta, que segundo ela seriam:

- Representações da EA: os diversos campos representativos da sua dimensão - ora compreendida como processo pedagógico em detrimento da natureza; 
ora estabelecida como gestão de recursos sem enfoque educacional;

- (Des)Envolvimento Humano: a luta contra a homegenização do termo "desenvolvimento sustentável" e do alto valor economicista nele explícito, [...] principalmente no intenso momento de globalização, onde o aparato tecnológico mascara as pluralidades regionais e robotiza os seres humanos;

- Uno ao Múltiplo: a dificuldade em sair dos nossos enclausuramentos teóricos na busca de diálogos entre as diversas áreas do conhecimento, reconhecendo que não existe, hoje, uma única área capaz de responder, sozinha, à dimensão da $E A$;

- Currículo fenomenológico: a necessidade de se criar espaços democráticos para o desenho curricular, em espaços abertos de avaliação e na aceitação da educação não-neutra e não homogênea, em detrimento da imposição dos Parâmetros Curriculares Nacionais (PCN);

- Educação inicial e continuada: a carência da introdução da EA nos currículos de graduação, pós-graduação e cursos de formação continuada, além de outros programas educacionais que versem sobre a formação de profissionais;

- Reflexão e ação: o abandono da insuficiência de refletirmos sobre nossas ações, através das ações pontuais e intervenções passageiras, para um estudo investigativo que permita a construção da pesquisa em EA (SATO, 2001, p. 19, grifos do autor).

Notoriamente há que se transpor muitos obstáculos, para que a prática da Educação Ambiental atinja aos objetivos a que se propõe. Por outro lado, tem-se a geografia que por sua vez, é uma disciplina cujo objeto de estudo compreende o estudo do espaço e suas ações humanas, bem como as consequências e implicações, dessas ações (os problemas ambientais). Não obstante ao ensinar Geografia haveria a possibilidade de desenvolver práticas de Educação Ambiental? Que recursos didáticos poderiam ser utilizados para o debate atual das questões ambientais, no ensino da Geografia?

Defendemos que o trabalho de conscientização ambiental envolve a ação integrada de todas as disciplinas, das diferentes áreas do conhecimento científico, onde há a necessidade de se adequar os conteúdos disciplinares já existentes para promoção do debate das necessidades ambientais do planeta. 
Nesse sentido, para Meirelles (2005) o desafio de um projeto de Educação Ambiental, está em incentivar as pessoas a se reconhecerem capazes de tomar atitudes. Para a tomada de atitude, há de se promover a reflexão crítica sobre os problemas ambientais em diferentes escalas, e nisso, a Geografia contribuiria de maneira peculiar.

\section{O ensino de Geografia como ponto de partida para a Educação Ambiental}

A geografia enquanto ciência, busca entender e explicar o espaço bem como as relações homem $x$ natureza, que se dão neste espaço, o ensino de geografia por sua vez, precisa extrapolar as questões da ciência geográfica, pois deve fornecer elementos para a formação do cidadão consciente e crítico, para tanto não basta conhecer o espaço e entender as relações que se dão no mesmo, é preciso que o educando se compreenda nesse espaço, como agente ativo e transformador, para que a partir deste saber e do nascimento de uma nova consciência, opte por posturas positivas em seu cotidiano. Porém sabe-se que entre a teoria e a prática temos um longo caminho a percorrer, conforme nos aponta Oliveira (2007):

A falta de discussão de propostas inovadoras dificulta a renovação do ensino, especialmente de geografia, pois a educação deve se orientar de forma decisiva para formar as gerações atuais, configurando novas possibilidades de ação. Isto nos remete a uma necessária reflexão sobre os desafios que estão sendo colocados para mudar as formas de pensar e de agir em torno da questão ambiental numa perspectiva contemporânea (OLIVEIRA, 2007, p.18).

De maneira que a formação de cidadãos conscientes e críticos passa pela compreensão do momento e do espaço em que este se insere, vemos que a escola tem papel fundamental na formação desses cidadãos e a geografia por natureza, abrange de forma muito eficaz o pensar o espaço e suas relações com a sociedade no decorrer da história.

Nossa sociedade hoje se encontra num processo onde os impactos ambientais tem afetado o bem-estar social, a cada dia sofremos as consequências de nossos atos impensados, logo a questão ambiental é uma das questões chave da contemporaneidade, merecendo nossa total atenção.

A geografia é, sem sombra de dúvidas, a única ciência que, desde a sua formação, se propôs ao estudo da relação entre os homens e o meio natural do planeta - meio ambiente, atualmente, em voga é propalado na perspectiva que engloba o meio natural e o social (MENDONÇA, 2004, p. 22-23). 
Os conteúdos de geografia estão recheados de assuntos que permeiam as questões ambientais, trabalha-se a apropriação do espaço, a distribuição do homem nele, questões políticas, sociais, populacionais e todos estes assuntos que são pensados e ensinados espacialmente também podem ser pensados e ensinados ambientalmente. Observando-se assim através destes as questões ambientais da atualidade, analisando criticamente as ações humanas do passado e planejando de forma consciente o futuro.

Partimos do consenso de que a Educação Ambiental é a chave para o desenvolvimento sustentável e que a geografia cujo objeto de estudo é o espaço geográfico ${ }^{4}$ é a ciência que detêm 0 poder de interagir harmoniosamente as questões pertinentes a Educação Ambiental, dando subsídios para que a formação do aluno seja significativa e eficaz. Mas como tornar o conhecimento significativo, interessante? Como transpor as barreiras da indiferença e do desinteresse do educando? O uso das novas tecnologias ${ }^{5}$ enquanto recurso didático, têm sido a aposta dos educadores nos diferentes níveis de ensino nos últimos anos.

\section{As novas tecnologias como ponte entre o saber e o interesse do aluno}

Nossas salas de aula estão repletas de possibilidades, temos a matéria prima para formarmos uma sociedade mais justa, participativa e consciente, porém nem sempre nos utilizamos das ferramentas adequadas para o realizarmos, as vezes insistimos na geografia meramente descritiva da escola tradicional, nossas metodologias nem sempre alcançam o interesse dos alunos, de forma que fica difícil criar uma consciência ambiental no aluno se este não se apropria da causa, não toma para si a responsabilidade porque não é estimulado adequadamente, e é para superar essa falha que as novas tecnologias vêm contribuir com o ensino de geografia e a Educação Ambiental, aguçando o interesse do aluno e possibilitando ao professor abordar de forma mais interessante e significativa o assunto a ser trabalhado.

Conforme Moran (2000):

Educar é colaborar para que professores e alunos nas escolas e organizações, transformem suas vidas em processos permanentes de aprendizagem [...] uma mudança qualitativa no processo de ensino/aprendizagem acontece quando conseguimos integrar dentro de uma visão inovadora todas as tecnologias: as telemáticas, as audiovisuais; as textuais, as orais, musicais, lúdicas e corporais (MORAN, 2000 P.15).

\footnotetext{
4 " Um conjunto indissociável de que participam de um lado, certo arranjo de objetos geográficos, objetos naturais e objetos sociais e, de outro, a vida que os preenche a anima, ou seja, a sociedade em movimento. O conteúdo (a sociedade) não é independente da forma (os conteúdos geográficos) e cada forma encerra uma fração de conteúdo. O espaço, por conseguinte, é isso: um conjunto de formas, contendo cada qual frações da sociedade em movimento" (SANTOS, 1994, p.26).

5 Entende-se como novas tecnologias como recursos didáticos o uso de dispositivos eletrônicos (notebooks, smartphones, projetores de mídias, tablets, câmeras fotográficas e de vídeo digitais, lousa digital e smartvs) e de aplicativos, softwares, redes sociais, entre outros.
}

revista brasileira educação ambiental 
Para Moran (2007, p.5) "as tecnologias são uma parte de um processo muito mais rico e complexo que é gostar de aprender e de ajudar a outros que aprendam numa sociedade em profunda transformação". O uso desses recursos justifica-se pelo fascínio que exercem sobre os alunos e por que tornam situações remotas e quase abstratas em assuntos compreensíveis e familiares por parte dos mesmos.

De fato, na sociedade capitalista, consumista e conectada, então como incutir nessas mentes a necessidade de consumirmos de forma consciente, de que é preciso cuidar de nosso planeta? Com certeza não é uma tarefa simples, porém não é impossível. Os recursos tecnológicos nas mais diversas formas podem trazer ao aluno o interesse, que ao nosso entendimento é meio caminho andado para $\circ$ aprendizado. Enfim, com tanta tecnologia e ferramentas gratuitas disponibilizadas na Web, cabe ao professor o papel de saber utilizálas para atrair o interesse dos jovens no uso dessas redes sociais favorecendo a sua própria aprendizagem de forma coletiva e interativa (BOHN, 2009, p.1).

Muitas vezes não olhamos com bons olhos os avanços tecnológicos ou até mesmo os novos métodos que surgem constantemente, mas embora reticentes diante do novo, nossa obrigação enquanto educadores é a de prepararmos nossos alunos para este mundo de novidades e principalmente dar-lhes subsídios para que se desvencilhem das armadilhas consumistas de nosso século, usando para isso de todos os recursos que nos são acessíveis.

\section{O papel do educador}

Se a Educação Ambiental está no topo da lista das necessidades educacionais, se o conhecimento geográfico é de extrema importância à formação do cidadão crítico, e no exercício de sua cidadania, se os recursos tecnológicos podem contribuir de forma positiva ao ensino de geografia, 0 professor é sem dúvida o elo que os une, esse elo tem a obrigação de ser forte para que se garanta o sucesso da empreitada. Para que haja aprendizado precisa haver interesse em aprender, dessa forma cabe ao professor tornar o conhecimento geográfico a ser aprendido, algo importante, algo significativo ao aluno.

Para Demo (1998, p. 167) a aprendizagem é construída sobre dois pilares, que são o esforço reconstrutivo do aluno e o segundo é proporcionado por uma ambiência humana favorável, que seria o papel do professor. Já para Moran, (2013) o grande desafio do educador é tornar a informação significativa, escolhendo aquelas que realmente são importantes entre todas as possibilidades, compreendendo-as de forma abrangente tornando-as parte de seu referencial.

Moran (2007, p.5) 
afirma que as tecnologias são uma parte de um processo muito mais rico e complexo que é gostar de aprender e de ajudar a outros que aprendam numa sociedade em profunda transformação", onde o professor será a ponte entre o aluno, as novas tecnologias e o aprendizado, dessa maneira existe a necessidade de aperfeiçoamento constante, para que a prática pedagógica seja condizente com as necessidades da sociedade em questão, e assim [...] "nas condições de verdadeira aprendizagem os educandos vão se transformando em reais sujeitos da construção e reconstrução do saber ensinado, ao lado do educador, igualmente sujeito do processo (FREIRE, 1996, p. 26).

Podemos dizer então que o conhecimento geográfico vem sendo produzido durante toda a história da humanidade, e que o uso que o homem faz do espaço se modifica conforme as necessidades vigentes em cada época, hoje a dominação do espaço se dá mais através dos recursos tecnológicos, que possibilitam a produção, o comércio, o transporte e a comunicação, do que pela posse do espaço propriamente dito, de forma que o professor de geografia cumpre efetivamente seu papel, quando propicia ao seu aluno conhecer e respeitar o mundo em que se insere, mesmo que este nunca saia de seu país, cidade, bairro ou até mesmo de sua sala de aula.

Saviani (1944, p.28) diz que "só se aprende de fato, quando se adquire um habitus, isto é, uma disposição permanente, ou, dito de outra forma, quando o objeto de aprendizagem se converte numa espécie de segunda natureza", esse deve ser o objetivo almejado pelo professor ao pensar e realizar sua prática pedagógica, produzir no aluno uma "segunda natureza" onde os hábitos de cuidado com o meio ambiente sejam inerentes a sua rotina.

\section{Considerações finais}

A tríade da sensibilização ambiental proposta até então, nesse ensaio, compreendeu a articulação entre o Ensino da Geografia, a Educação Ambiental e as Novas Tecnologias.

Tecemos nossos argumentos que, para a tomada de atitude frente às questões do consumismo desenfreado, aumento da quantidade de resíduos sólidos, dentre outros problemas ambientais, se faz necessário a formação da consciência ambiental, sob a perspectiva crítica.

Assim, para formar a consciência crítica é necessário o desenvolvimento do trabalho escolar integrado, isso compreende a participação das diferentes disciplinas e seus respectivos professores, bem como dos demais membros da comunidade escolar, pais e moradores (no caso de estudos de questões ambientais locais).

No ato de ensino da Geografia e promovendo a prática da Educação Ambiental, percebemos a possibilidade de aliar as novas tecnologias, 
possibilitando ao aluno interagir com outras realidades, trazendo subsídios ao professor e despertando o interesse do aluno, para que a partir desse ponto se estabeleça o aprendizado e a sensibilização. Pois ao otimizarmos a utilização das novas tecnologias aliadas ao ensino da Geografia e quem dirá até mesmo, as práticas de Educação Ambiental, possibilitaremos aos alunos a apropriação de novos conhecimentos historicamente produzidos.

\section{REFERÊNCIAS}

$\mathrm{BOHN}, \mathrm{V}$. As redes sociais no ensino: ampliando as interações sociais na web. Disponível em: http://www.conexaoprofessor.rj.gov.br/temas-especiais26h.asp. Acesso em: 15 de julho de 2013.

BRASIL. Ministério de educação e do Desporto. Lei no. 9.795 de 27 de abril de 1999. Dispõe sobre a Educação Ambiental, institui a política Nacional de Educação Ambiental e dá outras providências. Diário Oficial da República Federativa do Brasil, Brasília, n.79, 28 abr.1999.

CARVALHO, I.C.M.Educação Ambiental: Formação do Sujeito Ecológico. $2^{a}$ ed. São Paulo; Cortez, 2006.

DEMO, P. Questões para Teleducação. Petrópolis, RJ: Vozes, 1998. 365p

FREIRE, $\mathrm{P}$ Pedagogia da Autonomia. Saberes necessários à prática educativa. 35ed. São Paulo: Paz e Terra, 1996.

MEIRELLES, M.S.; SANTOS, M.T. Educação Ambiental uma Construção Participativa. $2^{\mathrm{a}}$ ed. São Paulo, 2005.

MORAN, J.M. Novos desafios na educação: a internet na educação virtual e presencial. Editora da UFPel, Pelotas, 2001, p.19-44.

MORAN, J.M. A TV digital e a integração das tecnologias na educação. Texto publicado no boletim 23 sobre Mídias Digitais do Programa Salto para o Futuro. TV Escola - SEED, novembro, 2007.

MORAN, J.M. Como utilizar a internet na educação. 1997. Disponível em: $<$ http://www.scielo.br/scielo.php?pid=s0100-

$19651997000200006 \&$ script=sci arttext.> Acesso em 22 de setembro de 2014.

MORAN, J.M., MASETTO, M.T., BEHRENS, M.A. Novas tecnologias e mediação pedagógica. Campinas, SP: Papirus, 2000.

OLIVEIRA, W.C. A contribuição da geografia para a Educação Ambiental: As relações entre a sociedade e a natureza no Distrito Federal. 2007. Dissertação de mestrado. Disponível em: http://bdtd.bce.unb.br/tedesimplificado/tde busca/arquivo.php?codArquivo=274 1 Acesso em 26 de junho de 2015.

SANTOS. M. Metamorfose do Espaço Habitado. 3.ed. São Paulo: Hucitec, 1994. 
SANTOS. M. A natureza do espaço: técnicas e tempo, razão e emoção. São Paulo: Hucitec, 1999.

SATO, M. Debatendo os desafios da Educação Ambiental. 2001. Disponível em: < http://www.partes.com.br/meio ambiente/educacao.htm> Acesso em: Outubro de 2015.

SAVIANI, D. Pedagogia Histórico-crítica: Primeiras aproximações. $3^{\circ}$ ed. São Paulo, SP: Cortez, 1944.

TORALES, M.A. A práxis da Educação Ambiental como processo de decisão pedagógica. Disponível em: http://dspace.usc.es/bitstream/10347/9496/1/b20101545.pdf Acesso em: 16 de junho de 2015.

VESTENA, C.L.B. Piaget e a questão ambiental: Sujeito epistêmico, diagnóstico e considerações educacionais. São Paulo, SP: Cultura acadêmica, 2003. 